\title{
Correction to: Mixed prototypes for the evaluation of usability and user experience: simulating an interactive electronic device
}

\author{
Fernanda Gomes Faust ${ }^{1} \cdot$ Tiago Catecati $^{1} \cdot$ Isabella de Souza Sierra ${ }^{2} \cdot$ Fernanda Steinbruch Araujo $^{2}$. \\ Alejandro Rafael García Ramírez ${ }^{3}$. Elton Moura Nickel ${ }^{2}$ - Marcelo Gitirana Gomes Ferreira ${ }^{2}$
}

Published online: 30 July 2018

(c) Springer-Verlag London Ltd., part of Springer Nature 2018

\section{Correction to: Virtual Reality https://doi.org/10.1007/s10055-018-0356-1}

In the original publication of the article, the following corrections have to be noted down.

\section{Section 3.3.5}

Is:

For the comparative evaluation of emotions that the product and its MP cause to users, we use expressive characters that represent a set of fourteen universal emotions, as proposed by Desmet (2003). Figure 11 shows these emotions as presented by Caicedo and Desmet (2009) and currently used in PrEmo ${ }^{\circledR}$ Instrument (a proprietary tool used to evaluate the user's emotional response when interacting with a product or interface).

\section{Should be:}

For the comparative evaluation of emotions that the product and its MP cause to users, we use expressive characters that represent a set of fourteen universal emotions, as proposed by Desmet et al. (2000) and Desmet (2003).

The original article can be found online at https://doi.org/10.1007/ s10055-018-0356-1.

Marcelo Gitirana Gomes Ferreira

marcelo.gitirana@gmail.com

1 Departamento de Engenharia de Produção e Sistemas, Universidade Federal de Santa Catarina, Campus Trindade, Florianópolis, Santa Catarina, Brazil

2 Departamento de Design, Universidade do Estado de Santa Catarina, Av. Buriti, 680, ap. 705B, Itacorubi, Florianópolis, Santa Catarina CEP 88.034-500, Brazil

3 Departamento de Computação Aplicada, Universidade do Vale do Itajaí, Campus Itajaí, Florianópolis, Santa Catarina, Brazil
Figure 11 shows these emotions as presented by Caicedo and Desmet (2009) and Laurans and Desmet (2017) and currently used in PrEmo ${ }^{\circledR}$ Instrument (a proprietary tool used to evaluate the user's emotional response when interacting with a product or interface).

\section{Legend from Figure 11}

Is:

Fig. 11 Fourteen universal feelings. (Reproduce with permission from Caicedo and Desmet 2009)

\section{Should be:}

Fig. 11 Fourteen universal feelings (reproduced with permission from Caicedo and Desmet 2009 and Laurans and Desmet 2017)

\section{Legend from Table 3}

Is:

Table 3 Emotional domains for expressive characters. (Reproduced with permission from Caicedo and Desmet 2009; Laurans and Desmet 2012)

\section{Should be:}

Table 3 Emotional domains for expressive characters (reproduced with permission from Caicedo and Desmet 2009; Laurans and Desmet 2017) 


\section{List of References}

\section{(exclude)}

Laurans G, Desmet P (2012) Indroducing PREMO2: new directions for the non-verbal measurement of emotion in design. Central Saint Martins College Of Arts \& Design, London, p 13

\section{(include)}

Desmet P, Hekkert P, Jacobs JJ (2000) When a car makes you smile: development and application of an instrument to measure product emotions. In NA-Advances in Consumer Research Vol. 27, eds. Stephen J. Hoch and Robert J. Meyer, Provo, UT: Association for Consumer Research, pp. 111-117.

Laurans G, Desmet P (2017) Developing 14 animated characters for non-verbal self-report of categorical emotions. J of Design Research, Vol. 15, No. 3/4, pp. 214 233. 